\title{
Four Wheeler Disc Brake Weight Reductions by Finite Element Analysis
}

\author{
Anjali Ashok Shinde ${ }^{1}$ \\ ME (Design) - Mechanical Engineering Department \\ JSPM's - R.S. College of Engineering, Pune, Maharashtra
}

\author{
Prof. Shailesh S Pimpale ${ }^{2}$ \\ ME (Design) - Mechanical Engineering Department \\ JSPM's - R.S College Engineering, Pune, Maharashtra
}

\begin{abstract}
Automotive organizations are paying their major interest in the weight optimization of components which reduced cost and manufacturing. Due to addition of safety feature the weight of the vehicle is going on increasing. The function of brake system is to decelerate a vehicle. The vehicle movement converted into heat while stopping wheel it is called an energy absorbing mechanism. Driver applies a force on brake pedal which is amplified by brake booster. A pressurizes brake fluid from master cylinder take active part as pedal pressed \& the hydraulic force developed by brake fluid is transmitted to calliper. The friction between material causes the rotating part to slow down and ultimately stop the vehicle. An optimization of 4 wheeler disc brake targeting reducing weight as objective function with required strength, frequency and stiffness is main scope of project.

Modal Analysis of the 4-wheeler disk Brake is performed to determine mode shapes and natural frequencies and also static analysis is performed to obtain optimized model from topology optimization technique from ANSYS. The 4 wheeler disc will be design in CATIA.
\end{abstract}

Keywords-Disc Brake, CATIA, ANSYS, Weight Reduction.

\section{INTRODUCTION}

Converting kinetic energy it into heat energy by uses frictional resistance to retard a motion is the main fundamental of A Brake. The disc brake is a type of braking system that uses a disc rotor is connected to the axle of wheel and a set of friction material called as brake pads (mounted on a component called brake calliper) is forced usually by hydraulic pressure against both sides of disc which causes it to stop with the help of friction. A braking system should have following properties:

i. The minimum stopping distance should be required in vehicle.

ii. All the wheels should be locked at the time of hard braking.

iii. The system must be leak proof.

iv. The weight of system should be low

Disc are uses (as opposed to rims or drums) as the braking surface. This type of brake is used on many types of Automobile vehicles. Reducing weight through topology optimization without exchanging with the required strength. The brake caliper, which houses pistons and brake pads, and the rotor are the major component of brake disc.Refer below figure for more details in Figure1. By reducing the weight of the vehicle we can improve the fuel consumption. When the mass of vehicle is reduced the inertial forces which has to be overcome by engine also reduces, and the energy required for vehicle to move is also less. Fuel consumption of vehicle is reduced by $4-8 \%$ by every $9-10 \%$ reduction in vehicle component. The reduction in mass of a brake disc is a small percentage of the total mass, but it is a collection of components that make up the total mass of the vehicle.

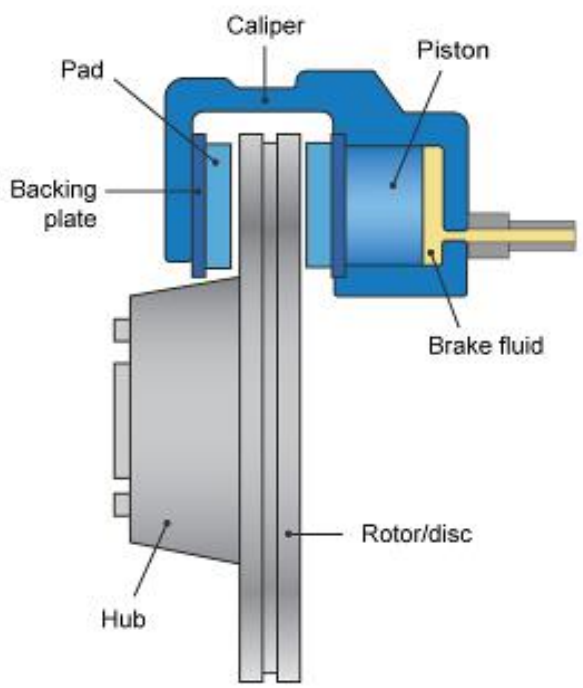

Fig.1 Disc Brake

\section{PROBLEM DEFINITION}

Nowadays, Topology optimization technique is used for weight optimization of components which reduces material cost and manufacturing. In present research 4-wheeler disc brake Tata Sumo Gold is to be studied under FEA to determine the optimum material removal from existing 4-wheeler disc brake under existing boundary condition and also determine changes in von misses stress and deformation with the topologies model. Natural frequencies are calculated to determine the nature of mode shapes at respective frequencies.

\section{LITERATURE REVIEW}

\section{QIFEI JIAN, YAN SHUI}

In the paper disc brake built on CATIA software. 3D model required for study purpose in analysis software. For experimental analysis use hard braking testing. Comparing both values are equal. The finite element analysis (FEA) system used for comparison between experimental values

Which give best result. The Temperature curve first increase \& decrease laterally. Reading found by temperature variation testing. The temperature of middle position is highest. In this paper, temperature curves of brake disc in radial and circumferential directions were obtained.The finite element analysis (FEA) was qualified, for better theoretical basis for further experimental analysis. By observation, the experimental values and simulation values were basically equal 
2. Mahfouz c,

The mathematical models used to study the dynamic behavior of a wedge disc brake. The friction coefficient, normal force and sliding speed set of test was directed. Setting time and Frequency response is aim of the dynamic behavior of a disc brake. The results indicate that friction coefficient significantly influence The resonance frequency and setting time of piece disc brake influence by friction coefficient. Coefficient of friction is same in both wedge disc brake \& conventional disc brake. Which effect decrease inclination angle. Decreases resonance frequency in both disc brake pad. The resonance frequency and setting time of wedge disc brake slightly influence by shoe factor .Mathematical model results finalize by value of friction coeffient.

\section{3 .R. Prashant Patel, Prof.M.A.Mohite}

In this paper Disc brake rotor design, optimize by thermal behavior analysis for weight \& cost reduction. The two different shape of disc are use for study. By giving different slot to disc brake are used for analysis. The objective of this paper is to design model in software and analyses the temperature distribution of rotor disc during braking operation using ANSYS software. Computational fluid dynamics (CFD) is used for experimental results.

In passenger cars brake disc should be in straight or curved and brake disc modifications are simply because knuckle tooling changes are very costly than brake disc. Design analysis by software \& result compare with experimental test by change in design as per analysis data. By using this methodology researcher achieve project objective.

4.Mr. Pravin Jawarikar, Dr. Subim n. Khan, Mr. Balaji. Kshirsagar,

This paper presents the different shapes two wheeler disc brake rotor are used for analysis with same function. The design is prepared in Pro-E and model analysis is done in Ansys. The shape optimization technique is used to find the optimum design solutions. The constraint for design is outer $\&$ inner diameter, mounting position of holes on wheel hub is considered. The best resolution out of improved rotor designs is finding out by comparing its results with the existing rotor. The optimize brake rotor is further investigated with the thermal and vibrational analysis. In weight reduction in disc achieved by cost reduction. Changing the geometry of the disc done by shape optimization. From the analytical heat dissipation calculation and the software thermal analysis it is found that the disc having maximum surface area will dissipate more heat and

low final temperature after braking. The CAE modal analysis is done and finding out the natural frequency of the optimized and existing disc at different mode shape. It is found that the optimized disc has the higher natural frequency. It is concluded that the component having less weight and same material properties in comparison has the higher natural frequency.

\section{LITERATURE GAP}

After evaluation of literature, it is clear that earlier all weight optimization research work were performed by Thermal analysis either by using different materials , Numerical solution create foe thermal , analysis optimization of disc brake rotor by CFD analysis. In none of the literature review papers mentioned about 4 wheeler disc brake weight optimization by structural analysis \& model analysis with help of numerical method. Here is a scope for obtained best optimized solution by topology optimization technique \& compared with existing model. Designing 4 wheeler disc brake $\&$ validate by the experimental technique.

\section{SOLUTION TO PROBLEM}

Solution of problem incorporated by Modal analysis of disc brake to obtain different mode shapes and natural frequency of existing 4-wheeler disc brake. Static structural analysis of disc brake is performed to determine deformation and equivalent stress. It is observed around maximum deformation and equivalent stress is within limit. An optimized model is obtained from topology optimization technique. It is determined that the region indicated in red region in topology optimization provides information regarding removal of material from that original mass.

\section{WHAT IS AVAILABLE IN MARKET}

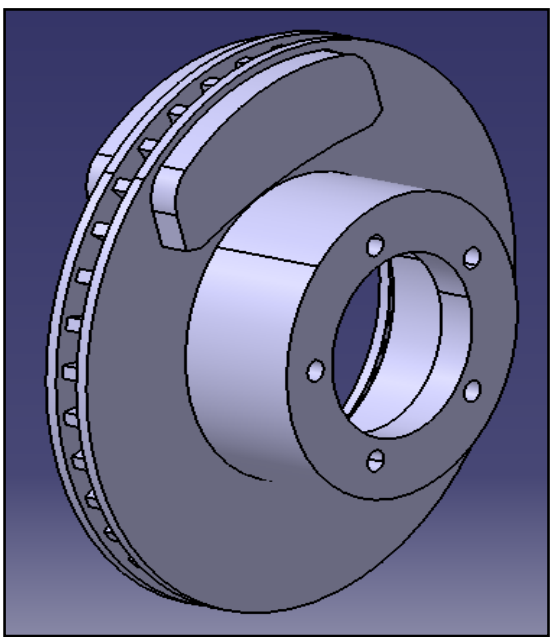

Fig.2 Disc brake

\section{OBJECTIVES OF PROJECT}

1. To determine mode shapes, natural frequency, deformation in 4-wheeler disc brake through finite element analysis by modal analysis in ANSYS.

2. To perform static structural analysis of disc brake to obtain deformation and von misses stress and shape optimized model from topology optimization.

3. Comparative study with Experimental test results \& analysis result will get proposed new design.

\section{SOFTWARE USED:}

1. CATIA 5.0: 3D modelling and 2D drawings.

2. ANSYS: WORK BENCH 14.5 for static structural analysis.

3. MS office-Excel, Word

\section{Part-1:}

\section{METHODOLOGY}

\section{Design and analysis of Four wheeler disc brake for weight optimization}

Design a lighter brake disc than the existing model used in four wheeler is main objective of this project. Nowadays, Topology optimization technique is used for weight optimization of components which reduces material cost and manufacturing.

In present research 4-wheeler disc brake Tata Sumo Gold is to be studied:- 
1. To prepare CAD design of existing 4-wheeler disc brake using CATIA V5 R20 software.

2. To determine mode shapes, natural frequency, deformation in 4-wheeler disc brake through finite element analysis by modal analysis in ANSYS 19.0.

3.To perform static structural analysis of disc brake under existing boundary condition to obtain deformation and von misses stress and optimized model from topology optimization. 4.The best optimized is to be obtained from topology optimization technique and compared to the existing model.

\section{Part- II :}

\section{Experimental analysis and testing of optimized Four Wheeler Disc Brake}

1. Experimental analysis of the disc brake rotor will be performed by fixing one side to determine mode shape and natural frequency using FFT analyses technique.

Comparison of experimental and analysis / numerical results.

\section{FUTURE WORK}

Design of lighter four wheeler disc brake for Sumo Gold Vehicle \& Analysis of complete Brake aggregates to reduce its weight and size.

Also next we are going to do comparative analysis of the existing and proposed four wheeler disc brake and save manufacturing cost \& its weight.

\section{REFERENCES}

[1] Transient temperature field of ventilated disc brake under the condition of hard by Numerical and experimental analysis of Qifei Jian, Yan Shui

[2] Dynamic behaviors of a wedge disc brake, Khaled R.M. Mahmoud, M. Mourad a, A. Bin Mahfouz c,

[3] Design optimization of passenger car front brake disc for improvement in thermal behavior, weight \& Cost reduction, Mr. Prashant Patel, Prof. M.A.Mohite

[4] Structural optimization, thermal and vibration analysis of two wheeler disc brake rotor Mr. Pravin n. Jawarikar, Dr. Subim n. Khan, Mr. Balaji Kshirsagar, 